2013-09-03

\title{
New Challenges for Strategy Development in Irish Higher Education Institutions.
}

\author{
Deirdre Lillis \\ Technological University Dublin, deirdre.lillis@tudublin.ie \\ Marion Lynch \\ Institute of Technology, Tralee
}

Follow this and additional works at: https://arrow.tudublin.ie/scschcomart

Part of the Educational Methods Commons, and the Higher Education Commons

\section{Recommended Citation}

Lillis, D. and Lynch, M. New challenges for strategy development in Irish higher education institutions. "Higher education policy", Sept. 2013. doi:10.1057/hep.2013.23

This Article is brought to you for free and open access by the School of Computer Sciences at ARROW@TU Dublin. It has been accepted for inclusion in Articles by an authorized administrator of ARROW@TU Dublin. For more information, please contact arrow.admin@tudublin.ie, aisling.coyne@tudublin.ie,gerard.connolly@tudublin.ie.

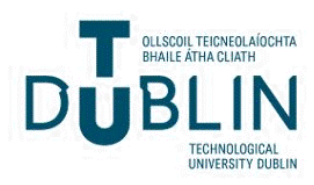




\title{
New Challenges for Strategy Development in Irish Higher Education Institutions
}

\author{
Deirdre Lillis and Marion Lynch
}

\author{
Corresponding Author:- \\ Dr. Deirdre Lillis \\ Head of School of Computer Science \\ Dublin Institute of Technology \\ Kevin Street, Dublin 8 \\ Email:
}

Tel: 014024607

Ms. Marion Lynch

Higher Education Policy Researcher

Institute of Technology, Tralee

Tralee, Co. Kerry, Ireland.

\begin{abstract}
Strategic planning has become an integral part of the management of higher education institutions worldwide. The experiences of all but one of the Republic of Ireland's 21 Universities and Institutes of Technology with strategic planning are explored from 2000-2010. At the starting point in 2000 only two Institutions had a documented strategic plan. Ten years later all had undergone one or more iterations of strategic planning. Qualitative research methods were used including document analysis of $n=42$ strategic plans, $n=12$ institutional review reports and $n=26$ interviews with senior managers with responsibility for strategic planning. The paper considers whether the strategic planning models used in the past decade will be able to meet the challenges presented by unprecedented economic circumstances and the new national strategy for higher education in Ireland. Significant deficits are identified with respect to strategic planning for institutional diversity, performance-related funding and external stakeholder engagement. Fundamental questions are raised in relation to the approaches taken to strategy development.
\end{abstract}

Keywords: higher education management, strategy development, strategic planning, national higher education strategy, Ireland. 


\section{Introduction and Context}

Higher education institutes worldwide (HEIs) are having to align themselves to an external environment which is exerting more pressure and are faced with a choice between managing change internally or having it dictated by external forces. If HEIs are to be the key enablers for their nation's policy objectives, to hold their own in a competitive funding landscape and to be the engines of growth in their regions their institutional management capability needs to be able to meet these challenges. Strategy development processes need to be effective, efficient and responsive to change, enabling HEIs to better serve the needs of all their stakeholders.

Strategic planning in higher education has many interesting and distinctive features when compared to the private sector or other areas of the public sector. It is a complex process whereby strategies for teaching, learning and stakeholder engagement are developed across a myriad of disciplines, in a turbulent environment and set against conflicting stakeholder demands. Strategic planning needs to both encompass the distinctive organisational culture in the 'academic heartland' (Clark 2004) and co-exist with the more established and more embedded quality assurance framework in Irish HEIs. While strategic planning is in widespread use there is little empirical research which demonstrates whether it is effective or otherwise in higher education (Lillis 2006). Much of the literature pertains to case studies of individual or small groups of institutions only, with some notable exceptions (Tabatoni et al. 2004; Thys-Clement \& Wilkins 1998; Rosa et al 2011). While such case studies have depth they are difficult to generalise from and the key contribution of this paper is its attempt to capture experiences of a national system of higher education over the course of a decade.

Between 2000 and 2010 most Irish HEIs ${ }^{1}$ undertook at least two iterations of strategic planning and all had been subject to at least one external quality review (institutional review) ${ }^{2}$. One informant per institution was selected purposefully on the basis of their role in strategic planning within their Institution $(n=20)$. Six of these informants were selected for a second round interview. The main limitation of the research is therefore its reliance on a single informant in each Institution. To counteract the potential for bias interviews were triangulated with extensive document analysis of strategic plans $(n=42)$ and institutional review reports $(n=12)$. As Irish HEIs share many characteristics with their international counterparts the findings may be generalisable beyond Ireland but are untested beyond the Irish context. A second limitation is that the research focused on the planning phase primarily and while informants' views of the effectiveness of the implementation phase were considered, these were not triangulated with other data sources. The research methodology required (Lillis 2006) to systematically and reliably evaluate the

1 For readability, the term 'Irish HEIs' will be used in this paper to denote the Institutions in the Republic of Ireland that participated in this study. This includes six of the seven Universities, Dublin Institute of Technology and the 13 Institutes of Technology. The study did not include a number of private colleges, teacher education colleges and others which operate in the Irish Higher Education sector. The term 'DIT/IOT' sector is used to refer to Dublin Institute of Technology and the 13 Institutes of Technology, all of whom participated in this research.

${ }^{2}$ For the University sector, institutional review was carried out by the EUA for the first cycle and the IUQB (Irish Universities Quality Board) for the second cycle. In the Institute of Technology sector institutional review was carried out by the Higher Education and Training Awards Council (HETAC) using its own methodology. In DIT institutional review was carried out by the NQAI using an EUA methodology for the first cycle. 
effectiveness of the implementation of strategic plans in $n=20$ Institutions was not a feasible approach to this research, given its aim of capturing the experiences of strategic planning in a national system.

\section{Higher Education in Ireland}

At the time of writing in 2012 the higher education sector in Ireland is comprised of seven universities, Dublin Institute of Technology, thirteen Institutes of Technology, seven specialist colleges and a small number of private colleges. Ireland has one of the highest educational participation rates in the world with over $81 \%$ of Irish students completing second-level education and over 60\% entering higher education (OECD 2010). Public expenditure on higher education is slightly less than the European Union (EU) average, graduates from Irish HEIs are considered the most employable in Europe and Ireland produces more graduates per 1,000 inhabitants than any other European country (Aubyn et al. 2009).

The Universities and the DIT/IOT sectors account for more than 95\% of the 193,000 publically-funded enrolments in higher education. Institution size range from the largest HEIs with over 20,000 enrolments to ten regional HEIs with less than 5,000 enrolments (HEA 2011b). Though appearing somewhat fragmented the latest available European data ranks Ireland as the fifth most efficient higher education system behind the United Kingdom, Japan, Netherlands and Finland (Aubyn et al. 2009). In terms of public expenditure on tertiary education as a percentage of GDP Ireland at 1.2\% spends less than the United Kingdom (1.7\%), the Netherlands (1.3\%) and Finland (1.7\%) (Aubyn et al. 2009). At the starting point of this study it could be considered a binary system by international standards but this boundary has become increasingly blurred in recent years. Within themselves the University and DIT/IOT sectors are relatively homogeneous in terms of their legislative and governance foundations (Government of Ireland 1994; Government of Ireland 1997; Government of Ireland 2006) and in terms of their funding and human resource management arrangements. The Higher Education Authority (HEA) has overseen both sectors since 2007 as the statutory funding, planning and policy development agency. A well-developed framework exists for quality assurance and the National Framework of Qualifications brings clarity to the interrelationships between various parts of the education system (NQAI 2001). Analyses are regularly undertaken by national agencies to determine the skills needs of the workforce and to establish national priorities for research and innovation.

At the starting point of this study only two Irish HEIs had a documented strategic plan but within ten years all had undergone one or more iterations of strategic planning to meet the requirements of a public sector reform initiative in 1994. The Strategic Management Initiative set a reform agenda for all parts of the Irish Public Sector which included delegation of authority and accountability, freedom of information, strategic development plans and performance management (Boyle \& Humphreys 2006). It was implemented initially through social partnership agreements with public sector trade unions of which the Programme for Prosperity and Fairness was most relevant for this research (Government of Ireland 1999) and further embedded in the higher 
education sector through changes to legislation for the Universities (Government of Ireland 1997) and DIT/IOT (Government of Ireland 2006).

The common starting point, on a clean slate so to speak, enhances the comparability of results and provides some basis for a 'Before and After' discussion of the findings. It is important to note also that the first national strategy for higher education in Ireland was not published until 2011 (HEA 2011a) and therefore individual HEIs were left to their own devices to interpret their environment and determine their own strategic direction during the 2000-2010 period. Had a national strategy been available it is arguable that strategic planning at institutional level could have focused more on interpretation, adaptation and implementation of prescribed national objectives.

A second consideration is that Irish HEIs would have had to rely upon the experiences of a small number of international HEIs, the wider public sector and the corporate sector for guidance when they embarked upon strategic planning for the first time. The expertise deficit is brought sharply into focus if one compares it to other higher education management processes such as the well elaborated framework for quality assurance articulated in the European Standards and Guidelines (ENQA 2005). Furthermore the relationship between strategic planning and the more established quality assurance framework is an important factor. The European University Association methodology for institutional evaluation intrinsically links planning and review, asking what an institution is trying to do, how it is trying to do it, how the institution knows it works and how the institution changes in order to improve (EUA 2012). Ideally feedback from the quality assurance system should inform decisions about what the institution is planning to do. Likewise strategic planning should take into account how the institution plans to improve quality. During the timeframe of this research all Irish HEIs underwent at least one institutional review process at the behest of their quality assurance agency. As there can be considerable overlap between strategic planning and institutional review this is considered in this paper.

Finally, it was only in the latter part of the decade that the HEA initiated an annual 'strategic dialogue' process with institutions in relation to an Institution's strategic objectives. At the time of writing the intended link between this strategic dialogue and subsequent funding allocations has not yet been implemented and therefore a key external driver which would have incentivised the successful implementation of strategic plans was absent during the decade in question.

\section{Environmental Trends and Issues}

Ireland presents a particularly interesting case study to explore the robustness of institutional strategic planning models to predict and prepare institutions for major changes in their environment. Ireland's economy crashed dramatically from the heights of the 'Celtic Tiger' boom in 2007 to the depths of a harsh and prevailing recession from 2008 onwards. The 'Celtic Tiger' period (2000-2007) saw GDP growth rates of between 5\% and 9\%, relatively low government debt to GDP ratios of $25 \%$ to $34 \%$ and low unemployment rates of $3 \%$ to $4 \%$. During the decade the higher education sector received substantial investment in capital projects, research funding and 
through a Strategic Innovation Fund. After the economic crisis in 2008 Ireland was the first Eurozone country to accept an aid package from the European Union, European Central Bank and International Monetary Fund in 2010 and should the terms of this be implemented in full, Ireland will undergo seven successive years of austerity by 2015. The crisis brought a sharp reversal of trends on these three key economic indicators and IMF projections to 2017 paint a grim picture. Growth in GDP is $0.5 \%$ in 2012 with projections of a small rise to $2.5 \%$ by 2017 . Unemployment is expected to peak at $14.5 \%$ in 2012 and drop slowly to $11 \%$ by 2017. The Government Debt to GDP ratio is $113 \%$ in 2012 and will decrease marginally to 109\% in 2017 . The impacts of the financial crisis on the Irish education system are considered in full in Lillis and Morgan (2012).

Regardless of economic fortunes, investment in education remains a constant in terms of its perceived value to Ireland and it is seen as critical to the economic recovery of the country. However economic constraints will a major factor for all sectors in the coming years. In addition there is a projected increase in demand for higher education places (new entrants) between 2009 and 2019/20 of 7\% (McGuinness et al. 2012). Labour market activation measures to address high unemployment rates are likely to feature in national strategies and there will be pressure on HEIs to continue to diversify their funding sources. This external environment will present unprecedented challenges for strategic planning within institutions and it is worth mentioning that no strategic plan of any Irish HEI in the 2000-2007 period predicted the economic crash in 2008. In their defence, Irish HEIs were not alone in this however it does call into question the robustness of the strategic planning models used.

\section{The Experiences of Irish HEIs with Strategic Planning}

The experiences of Irish HEIs over the ten year period are considered in terms of the approaches taken to strategy development, whether the strategic planning models used were fit for purpose and how the process was undertaken within Institutions.

\section{Approaches to Strategy Development}

A fundamental distinction between the development of strategy and strategic planning must be drawn from the outset. Whittington contends that there are four approaches to strategy development which are differentiated by (i) the degree to which the outcomes are intended and (ii) whether the processes used are deliberate or emergent (Whittington 2001) (Figure 1).

Figure 4 Approaches to strategy development - Adapted from Whittington (2001)

The classical approach to strategy development, dubbed Masters of Our Universe, assumes that deliberate planning is vital to future success, that changes in the environment can be mastered and that the future can be predicted with certainty (Table 1). This approach dominates higher education as evidenced by strategic plans which articulate a long-term vision, goals, objectives and targets. In stark contrast the evolutionary approach argues that the development of long-term strategy is futile and that a singular goal of Survival of the Fittest in the marketplace is the most 
appropriate approach (Table 1). It is arguably more suited to HEIs which depend solely on tuitionfee income, or research institutes which depend on competitive funding, who need to be able to adapt flexibly to market opportunities to survive.

The systemic approach, Play by Local Rules, asserts that deliberate strategy development is important, that it can result in multiple outcomes (both intended and unintended) and that the particular social context is an important consideration (Table 1). It is arguable that the bedrock of quality assurance in higher education, self-evaluation with peer review, exhibits many of the characteristics of the systemic approach. Such reviews are often conducted in a 'bottom-up' manner, rely on expert opinion and are sensitive to the organisational culture in the academic heartland. The processual approach, Go with the Flow, contends that strategy is driven by multiple outcomes (e.g. individual ambition, professional pride, managerial power, patriotism, culture and religion). Strategy development is seen as a pragmatic process of mistakes, learning and compromise.

\section{Table 1 What constitutes strategy? Adapted from Whittington (2001)}

Shades of all four approaches will be evident in any individual effort. It is worth noting that success in one approach could be considered failure in another. Successfully implementing every objective of a classical 5-year strategic plan could be considered a failure from evolutionary perspective if important changes in the environment were ignored in the interim. The key point is that there are alternative approaches available to HEIs to develop strategy, up to and including not undertaking a strategic planning process.

In general the most fundamental choice for an organisation with respect to the development of strategy is therefore 'to plan or not to plan?'. This choice was not available to Irish HEIs as they were required to undertake a deliberate strategic planning process to meet an external requirement, which places them in either the Classical or Systemic quadrant (Figure 1). Approximately one third of Irish HEIs $(n=6)$ explicitly stated that they used a rational strategic planning model which is an inherently classical approach to strategy development. This consists of environmental scanning followed by a set of linear stages (the development of vision, mission, goals and objectives). Strategy implementation is seen as a distinct phase with action plans cascading from the objectives. A further fifth of Irish HEIs $(n=4)$ used scenario/foresight planning models which are more creative than rational planning in that a set of alternative futures are imagined before the most probable future(s) are selected. Scenario planning can also be considered a Classical approach as a deliberate attempt is made to plan and to set goals. When the DIT/IOT sector collaborated in the latter part of the decade to produce guidelines on strategic planning these were essentially a classical approach (IOTI 2011). In a similar initiative in the University sector, the IUQB published guidelines on strategic planning that were also highly prescriptive (IUQB 2008). The findings suggest therefore that a predominantly Classical approach to strategy development was adopted in all Irish HEIs.

There is one caveat. Nearly all institutions $(n=18)$ involved their academic community in strategic planning though the extent and nature of their involvement differed. Some explicitly 
reported the percentage of staff participation in their plans $(\mathrm{n}=8)$ and although this ranged from $12 \%$ to $85 \%$ its inclusion suggests it was an important metric. This suggests that the 'Local Rules' of an organisational culture which expects collegiality and consultation were respected.

In general however it can be said that the Classical Masters of the Universe approach predominated in Irish HEIs with some aspects of the systemic approach also evident. This is a key finding as it provides a common framework to analyse the strategic planning models in use and enhances the generalisability of the findings as the classical approach predominates the literature in higher education management to the point that it is almost synonymous with strategic planning. Higher education is not alone in this as the classical approach to strategic planning is consistently rated as one of the most influential management tools in the private sector (Bain \& Company 2007).

The main criticism of the Classical approach is that it assumes a stable environment where extreme change and unexpected events, like the economic crash in 2008, are not accounted for. A number of authors question the appropriateness of rational planning in a higher education (Bruton 1987; Thys-Clement \& Wilkin 1998; Bayenet et al. 2000; Birnbaum 2000; Tabatoni et al. 2004; Lillis 2006). The analytic nature of the rational approach is at odds with the known difficulties relating to the use of quantitative performance measurement in higher education. Market forces are increasingly important suggesting that elements of the evolutionary approach may be appropriate in some contexts (Bayenet et al. 2000). Fundamentally one has to question the degree to which the variety of stakeholders and their competing demands, the myriad of trends and issues in the environment and the internal politics within a HEI can be mastered and predicted with the certainty implied in the classical approach. The variables involved are at least complex enough to pose the question whether they have reached the cognitive limits of human minds.

A key finding from this research was that that four fifths $(n=16)$ of Irish HEIs did not evaluate alternative strategic planning models prior to selecting one for their context. More than two-thirds of informants $(n=13)$ did not demonstrate an awareness of alternative strategic planning models which is surprising given that all informants had significant levels of responsibility for strategic planning in their institution. In addition external consultants were employed by nearly half of Irish HEIs $(n=9)$ to assist with strategic planning and one fifth of institutions $(n=4)$ relied upon consultants to select the strategic planning model. Eight Irish HEIs designed/adapted what they described as an 'in-house' model. In second/subsequent iterations, it is clear that HEIs learned from their experience and made modifications to their strategic planning processes but none questioned their fundamental approach to strategy development. Overall there was a lack of rigour in the evaluation, selection and design of strategic planning models which has significant implications for the next decade.

\section{Purposes of Strategic Planning}

In a classical or systemic approach to strategy development the main purposes of strategic planning are to clarify or create the mission and vision of an organisation, align the organisation to its environment, mobilise its internal capacity toward achieving the vision and articulate a pathway by which the vision can be achieved. Strategy development in higher education is complex in that 
a broad range of interrelated activities in the core functions of teaching and research must be considered across a range of academic disciplines. Engagement with stakeholders in industry and the wider community, to support the teaching and research missions, has strengthened it's claim on being a core activity of HEIs in recent years (Alves et al. 2010). This is particularly true of the DIT/IOT sector in Ireland and engagement with stakeholders is copper-fastened as a priority in the new Irish national strategy for higher education (HEA 2011a).

A mission statement articulates the purpose of an organisation and although various planning models differ on when, how and where in the organisation the mission should be formulated, they agree that consideration of mission is an integral part of the process. Like many of their international counterparts, Irish HEIs are required to operate within a well-defined legislative framework which places boundaries on their potential mission (e.g. Irish HEIs are not permitted to compete directly with commercial entities or to choose their quality assurance/accreditation agency). By the end of the decade all Irish HEIs had documented a mission statement and more than half $(\mathrm{n}=11)$ developed more focused and distinctive mission statements in second/subsequent iterations of strategic planning.

A vision statement represents a desired future and considers the uniqueness or distinctiveness of an organisation with reference to its position in the external environment, taking into account competitors, comparators and other influencing factors. Approximately half of Irish HEIs $(n=9)$ did not document a vision statement in their first iteration of strategic planning. This is somewhat at odds with the three-quarters of informants $(n=16)$ who believed that strategic planning had resulted in a clear vision for their institution. It is possible that in the first iteration the mission statement served a dual purpose or that the vision was articulated through strategic goals. In second/subsequent iterations a further five institutions documented a vision statement which indicates a growing realisation of its importance. Most institutional review panels commented on the vision and mission of the institution, or its absence, in their reports. One panel noted for example that, other than the vision of the President,

"the EUA team did not encounter many other visions of the future of the university and its different components for the next five to ten years. The team did not expect to find one shared global vision of the future, but a number of converging ideas which together would help create a common set of explicit institutional objectives for the mid to long term. This did not appear to be the case..."

Given the relatively homogenous nature of Irish higher education by international standards, with 21 publically funded HEIs deriving their functions from two Acts in legislation, it is arguable that achieving a truly unique vision beyond a specific geographical region is difficult. Kuenssberg (2011) found for example that the mission statements of Scottish universities convey an overall impression of sameness rather than distinctiveness. In contrast James and Huisman (2009) found that mission statements in Welsh HEIs demonstrated a considerable level of diversity and exhibited strong awareness of market forces. It is possible therefore to make a HEI distinctive by focusing on certain disciplines, emphasising aspects of its mission, through its responsiveness to the market, its engagement with the stakeholders it serves or by carrying out its work in a particular way. 
Informants in Irish HEIs had mixed views on whether their institution's vision was unique with $n=8$ believing it was. Five of these were from the university sector which may suggest that universities strive for uniqueness within their national and/or international sphere whereas the IOTs may believe they are sufficiently differentiated by their regional location. The lone informant from the university sector who believed their vision was not unique stated that

"One of the biggest issues with planning in universities is you could take six or seven university plans, take the names off them, shuffle them and you wouldn't know the difference between them"

A more fundamental question underpins this as it is unclear how Irish HEIs objectively assess the uniqueness/distinctiveness of their mission/vision as the vast majority $(n=18)$ did not undertake a competitor analysis as part of their strategic planning. An example of a competitor analysis model is Porter's Five Forces Framework (Porter 1985). In a higher education context this framework would examine the environment for threats from existing HEIs, new/substitute providers and the power of student choice and funding agencies. Porter (1985) cautions against being 'all things to all people' and recommends that organisations differentiate themselves within a defined market segment. This finding has particular significance for the new landscape for Irish higher education which will be discussed in the final section.

One of the main purposes of strategic planning is to evaluate an organisation's capacity to develop within its external environment. In the absence of a national strategy during the decade in question Irish HEIs had to interpret their external environment for themselves. In a classical approach this is commonly undertaken using an IPEST analysis where international, political, economic, socio-cultural and technological factors in the external environment are considered (Johnson and Scholes 2002). One third of Irish HEIs $(n=6)$ undertook an explicit IPEST analysis with all of the remaining institutions considering some/all of the typical IPEST factors. Political factors, including national education policy, were the most common factors considered by Institutions ( $n=14)$ followed by social $(n=9)$ and economic factors $(n=8)$. The emphasis on political factors might suggest more emphasis be given to a Processual Go with the Flow approach to strategy development.

In a classical approach an objective assessment of the internal capacity of an organisation is undertaken, often by examining its strengths and weaknesses, opportunities and threats using a SWOT analysis (Johnson and Scholes 2002). Eight informants explicitly referred undertaking a SWOT analysis with the most prominent internal factor considered being resources, followed by internal restructuring, student numbers, participation rates, retention rates and changing student cohorts.

Whether a strategic plan is fit for purpose depends to a large extent upon whether the goals and objectives developed are appropriate. Goals are high-level and long-term aims and in higher education they need to be broad enough to cover the areas of teaching, research and engagement. Objectives are shorter-term and more focused (Johnson and Scholes 2002). In this study an appropriate goal/objective was one which (i) was clearly linked to the vision/mission (ii) that addressed issues raised in the internal and external analysis and (iii) that was realistic and achievable. While there was considerable variance in the structure and presentation of the strategic plan documents, all contained goals and objectives that were in line with their legislative 
mission. There was a strong emphasis on the teaching and research mission as would be expected. There was also significant attention paid to external engagement with industry and community stakeholders, technology transfer and innovation initiatives, internationalisation, partnerships with other HEIs and other stakeholders. Most plans also had explicit goals for enabling factors such as human resources, finance, campus development and the learning environment for students. A detailed analysis of the structure and content of the strategic plans is the subject of a future paper.

Three quarters of informants $(n=16)$ believed their institution's goals and objectives were appropriate though their level of certainty wavered. Five of these informants noted at a later stage in the interview that their strategic plan should have been more focused with fewer goals. Some informants suggested that the goals were appropriate because they were all encompassing which runs contrary to Porter's (1985) contention that organisations should avoid being all things to all people. Half of the informants $(n=10)$ stated that the objectives of the strategic plan are realistic and achievable though three of these admitted that they would not be completed within the specified timeframe.

What is less obvious from the analysis is how Irish HEIs prioritise between goals and objectives. This is partly because the implementation phase was beyond the scope of this study but it is arguable that the strategic plan itself should give some sense of this. Research for example is of more importance to the university sector than the Institute of Technology sector but this is not evident from the plans. The strategic choice phase of strategic planning which involves prioritisation and risk assessment appears to be under-developed which has consequences in the new landscape for envisaged for higher education in Ireland as will be discussed in the final section.

\section{How was Strategic Planning Undertaken?}

Given the inherent lack of responsiveness to changes in the external environment in the classical/rational approach to strategy development the length of time strategic planning takes is an important consideration. Nearly half of Irish HEIs completed their initial strategic planning process in twelve months or less, with outliers ranging from 3 months to two years. On average one fifth of the typical five-year cycle was spent on the planning phase.

Governing Bodies generally instigated the planning process and thereafter their role included monitoring, oversight and final approval of the plan. In nearly all Irish HEIs the President and senior management teams had significant involvement with the development of the strategic plan as would be expected. In all Irish HEIs the strategic planning process was led by staff in senior management positions. One third of institutions created a new full-time position, a 'Head of Institutional Strategic Planning'. In the remaining institutions senior managers were assigned responsibility for strategic planning on a part-time basis. Despite the fact that the sectors are relatively homogenous (within themselves) there is little consistency of approach apparent and it is possible that decisions were influenced by individual skillsets and workloads as opposed to an evaluation of where the position best fit in the organisational structure. It is noteworthy also that nearly three quarters of the institutions did not employ somebody with specific expertise in this area but rather gave the task to an existing member of staff. No Irish HEI positioned its strategic 
planning office in or alongside its quality assurance office for example, although it can be argued that there is considerable overlap in planning and review work (Lillis 2007).

Staff involvement has been noted as particularly important in strategic planning in higher education (Allen 2003; Baynet et al. 2000; Birnbaum 2000; Davies 2004; Henkel 2004. Tabatoni et al. 2004;). In all but one HEI there was a high level of involvement by staff at all levels (senior management, middle management and academic staff) and all roles (academic, administrative, technical and support). A wide range of methods were used to engage staff by Institutions. Table 2 outlines the number of institutions that utilised a particular method of involving various stakeholders with most institutions using more than one method. It is worth noting that some methods are more effective than others (e.g. a small workgroup on a specific theme versus an 100page email attachment). Given the importance of consultation and collegiality in the academic heartland further research into the effectiveness of staff engagement methods would be a useful exercise.

\section{Table 2 Nature of staff, student and stakeholder involvement}

The majority of informants ( $n=13)$ felt that staff involvement had been good and while staff engagement was clearly important to Irish HEIs what is less clear was the level of commitment to the process. Senge (1990) describes seven levels of staff commitment ranging from Commitment (staff who will do whatever it takes to complete a task), to Formal Compliance (those who do what is expected and no more) to Apathy (those who have no interest). It is noteworthy also that separate structures and processes for strategic planning were created in all HEIs. There is an argument that with careful design, strategic planning could have been 'baked into' into normal operations such as existing management meetings, academic council meetings, governing body meetings, School boards, programme team meetings and other quality assurance processes.

In most international quality assurance frameworks, the student voice is a strong feature and student representation on statutory academic councils and governing bodies is the norm in Ireland. By comparison, though many Irish HEIs involved students in their strategic planning process (Table 2), both informants and documents were vague on the nature of their involvement. Some students may have been involved in the strategic planning process by default as they sit on the Governing Body and Academic Council. This differs from deliberately seeking student feedback as part of the strategic planning process. In general the student voice in strategic planning was considerably less than one would expect in quality assurance processes. It is fair to say however that if students are viewed as customers or consumers of higher education their involvement in strategic planning would not be necessary.

A stakeholder approach to strategic management suggests that organisations need to satisfy all stakeholders that have an interest in the organisation and focus only on those stakeholders (Freeman 2010). By concentrating on the active management of these key relationships the interests of external shareholders can be managed in such as way as to ensure the long-term success of the organisation. The involvement of industry and other external stakeholders in the strategic planning process does not seem to have been as important to Irish HEIs as the involvement of staff and students. Half of the informants $(n=11)$ stated that industry 
stakeholders were involved through workshops, focus groups, presentations and meetings. Stakeholder involvement from the wider community was not widespread in the strategic planning process. It could be argued that if stakeholder feedback is captured effectively as part of ongoing operations then there is no need to seek it out explicitly as part of the strategic planning process. However no Irish HEI employed a stakeholder approach to strategic planning or setting mutual goals and objectives with key stakeholders.

\section{How did strategic planning integrate with quality assurance?}

An integrated strategic planning and quality assurance system would see feedback from the quality assurance system informing strategic goals and objectives and strategic planning would include objectives about how quality could be improved. The research found that the level of integration between strategic planning and quality in Irish HEIs was generally quite low. One third of informants $(n=6)$ stated that quality and planning were not integrated in their institution. Of those who believed that quality and planning were integrated, when pressed further, only two could give concrete examples of how and where this integration had occurred. The reports from two institutional review panels who used the EUA methodology (EUA 2012) made explicit recommendations in relation to this:-

“... a more explicit link by the university executive between the Quality Review Process $(Q R P)$ outcomes and strategic management (is needed)”

"Use the Quality Assurance/Quality Improvement process and results, together with an increased institutional research capacity, to support strategic planning and actions"

During the timeframe of this research all Irish HEIs underwent at least one institutional review process at the behest of their quality assurance agency. As there can be considerable overlap between strategic planning and institutional review it is important to investigate this further (Lillis 2007). At its simplest level institutional review can be considered a 'Review-PlanImplement' model whereas strategic planning is essentially a 'Plan-Implement-Review' model (Figure 2).

\section{Figure 2 The relationship between strategic planning and institutional review}

The knowledge produced by both processes about the challenges facing the institution and the necessary responses can be broadly similar although their methodologies and presentation may differ. For example there is overlap between the evidence required to support the selfevaluation phase of institutional review and the external analysis (IPEST) and internal analysis (SWOT) phase of strategic planning. Similarly the institution's response to the peer review panel's recommendations should inform the goals and objectives of strategic plans. Both processes are expensive undertakings in terms of the time invested by participants therefore there is a strong case to be made to streamline the overlap between them and to increase the alignment of their outcomes. The contention here is that with some careful thought about process design is that there is at least enough overlap to merit their integration at component level. 
Content analysis of the interviews demonstrated that 'institutional review' was mentioned by only $n=2$ informants (all of who had responsibility for strategic planning in their institution). Although all Irish HEIs underwent at least one institutional review during the decade no institution considered how strategy development might be undertaken, even in part, by their institutional review process. Using an 'indigenous' higher education process, self-evaluation with peer review, to develop strategy, would be characteristic of the systemic Play by Local Rules approach to strategy development.

\section{Challenges for Strategy Development in the New Landscape for Higher Education in Ireland}

The experiences of Irish HEIs of strategy development over the last decade can be summarised as follows. It was initiated within institutions in response to an external requirement and once initiated strategic planning continued with little evaluation of its effectiveness. Few attempts were made to integrate it with the more established and more embedded quality assurance system. The classical/rational approach to strategic planning predominated and alternatives, such as evolutionary or systemic approaches to strategy development, were not considered in earnest. Though there was ample consideration of the external environment in most institutions, the strategic planning models used did not prepare Irish HEIs for major changes such as the economic crisis in 2008. Irish HEIs struggled to articulate a distinctive vision in relation to their positioning in the higher education landscape and the risk assessment and prioritisation phase of strategic planning was under-developed. While staff were involved the process, students and external stakeholders had a limited role in shaping strategy.

Despite the growing experience with strategic planning over the decade, it can therefore be argued there are significant limitations to current internal strategic planning models. This section considers how two of these limitations can be addressed - namely (i) creating a distinctive vision/mission and (ii) engaging external stakeholders. It is important to highlight that these are considered only in the context of how the predominant classical/rational approach to strategic planning can be enhanced. The findings of this research point to the need for a much broader debate about how we develop strategy in higher education, a debate which needs to include national funding and quality assurance agencies.

\section{The New Landscape of Irish Higher Education}

The economic challenges facing Ireland in the short to medium term are unprecedented. Despite the value placed by the Irish public on a quality education system, it is unlikely that any sector will escape the austerity measures which are required to reduce the national budget deficit from a projected $10.3 \%$ of GDP in 2011 to less than 3\% in 2015. While the higher education sector may see its overall funding maintained, it will be expected to meet increased demand from demographics from within this funding envelope. Where discretionary funding is available it is 
likely to be 'top-sliced' for targeted initiatives to address high unemployment and emigration rates. Publically-funded HEIs will have to compete with their private sector counterparts for their share of such initiatives and, in line with international trends $s_{2}$ Irish HEIs will have to generate greater percentages of their income from private sources to reduce their dependence on exchequerfunding. Competing for funding with other HEIs, attracting investment from industry and pursuing the international student market will amplify the concept of risk management within institutions. In addition, economic challenges may see the re-introduction of tuition fees, which is a particularly emotive issue for the Irish public and one which could be considered a litmus test for austerity measures in education. This would strengthen the concept of the 'market' in Irish higher education and level the playing pitch with private colleges. The immediate challenge is to 'do more with less'. The more onerous challenge however will be to 'do things differently'.

The first national strategy for higher education (HEA 2011a) was developed as the economic crisis was unfolding and it will be implemented in this harsh economic climate. Engagement with external stakeholders was highlighted as a 'third pillar' of activity of equal esteem to teaching and research. Internationalisation and part-time education were given increased emphasis. The national strategy is revolutionary in its recommendations for the national system structure, funding arrangements and institutional governance and management. The strategy envisages an enhanced role for the HEA in steering the system (in contrast to a recommendation in an earlier public sector rationalisation report, suggesting it should be abolished).

The new funding framework introduces a performance-based element for the first time to be implemented through an annual 'Strategic Dialogue' between HEIs and the Higher Education Authority (HEA 2011a). As part of this, HEIs will report on their performance in five dimensions (i) distinctiveness of mission (ii) alignment to national priorities (iii) institutional performance against key indicators (iv) regional cluster context and (v) engagement with external stakeholders. Similar principles will underpin the allocation of research funding (Government of Ireland 2011).

The national strategy envisages a consolidated but diverse sector comprised of institutions with distinctive and complimentary missions attuned to the needs of their regions. A fundamental review of the nature of HEIs in Ireland is envisaged with the stated aim of consolidation to an (unspecified) number of institutions with sufficient scale, diversity of mission and capacity to meet economic and societal needs. Co-ordination of the sector will be partially achieved through the formation of 'regional clusters' of collaborating institutions (which may include universities, Institutes of Technology and other providers). A new kind of HEI, a Technological University, has been outlined as a possible trajectory for a small number of larger Institutes of Technology. Collaborations and mergers of smaller Institutes within a regional cluster are encouraged. For the first time, all quality assurance will fall under the remit of a single agency, Qualifications and Quality Assurance Ireland (QQI). Irrespective of its original intent, given the current economic imperatives, it is destined to become a rationalisation agenda in all but name. 


\section{Enhancing the Rational Strategic Planning Approach}

The challenges facing Irish HEIs in the short to medium term are therefore unprecedented in the history of the Irish State. At national level Ireland is moving from a bottom-up and laissezfaire system to top-down and nationally-steered, in a system that did not have a national strategy for higher education until 2011. The strategic dialogue process with the HEA will move strategic planning from being a necessary evil on the periphery of institutional management to the centre stage. Strategic planning models will need to be far more rigourous and robust with clear links to decision making as its outcomes will be directly linked to funding. For the strategic dialogue process to be credible Irish HEIs will have to transparently demonstrate their performance to their funding agency and the HEA will have to demonstrate its capacity to conduct the strategic dialogue process meaningfully with more than 20 institutions. Both the HEA and Irish HEIs will need to be able to communicate this performance to stakeholders in an open and transparent manner, in a way which will also have to withstand the scrutiny of peers, whose own funding allocations may be impacted in an environment of declining resources.

Somewhat paradoxically, the opportunity to seek designation as a Technological University is arguably a counterweight to the promotion of diversity within the sector. During the last decade DIT, WIT and CIT, the three largest Institutes of Technology made formal applications for university status. The remaining 11 IOTs perceive themselves to be equal in most aspects of their work and if one IOT were to seek TU status it is likely that all others would follow suit. Explicit criteria have been set for TU status (HEA 2012) and it is arguable that the pursuit these targets will amplify the rational approach to strategy development and force conformity to one type of institution. HEIs will work toward whatever is rewarded in funding arrangements and institutional status.

Despite the growing experience and expertise within Irish HEIs of strategic planning, it is becoming a more, not less, complex process. All trends point to increased dependency on this internal management process within institutions and enhancements to the rational strategic planning approach are therefore necessary to address the limitations identified by this research.

\section{Creating a distinctive vision/mission}

This research demonstrated that Irish HEIs struggled to articulate a unique/distinctive vision for their institutions. Even when informants thought this had been achieved, a competitor analysis which would provide an evidence base for any assertions of distinctiveness was absent. This research also found that the concept of strategic choice or prioritisation was under-developed. With a greater emphasis on distinctiveness of mission and performance against strategic objectives Irish HEIs will struggle to remain 'all things to all people'. Much greater emphasis on strategic choice and risk management is required in future strategic planning models than is currently the case.

While Irish HEIs come to grips with fully understanding diversity in the new landscape, and to finding their niches within it, their strategic planning models need to emphasise the development of an institutional profile which measures distinctiveness. Irish HEIs will need greater knowledge of themselves and their competitors, at the very least within a regional cluster. 
A broad definition of diversity will be required, such as the criteria outlined in the EU U-Map project (van Vught et al. 2010), which provides a mechanism to compare HEIs using indicators which include teaching and learning, student profile, research involvement, involvement in knowledge exchange, international orientation and regional engagement. Adaptions of techniques such as Porter's Five Forces Framework (Porter 1985), which systematically analyses other players in an organisation's environment, could provide a basis upon which to build this knowledge.

\section{Engaging external stakeholders}

The national strategy envisages a small number of regional clusters of HEIs with a coordinated approach to industry and other stakeholders within their region. In a fully-fledged regional cluster one could envisage HEIs formally setting shared strategic goals with major employers, development agencies, local authorities, community groups and second/further education providers to build a regional brand or to tackle specific problems like unemployment. In a regional cluster they may even have to formally set shared goals with other HEIs. While Irish HEIs work with external stakeholders on a daily basis and seek formal and informal feedback through many channels, this research found that the level of explicit external stakeholder involvement in strategic planning processes was low. A stakeholder-driven approach to strategic planning (Freeman 2010) would include a comprehensive stakeholder analysis as a core component of the model, identifying and prioritising the most important stakeholders of the Institution. The planning process would ensure engagement with these key stakeholders in the formulation of the institution's strategic goals and objectives, and could go so far as to set shared goals with key stakeholders. In a stakeholder approach to strategic management the question for an institution is less about 'What do we want to be?' and more about 'What do our stakeholders need us to be?'. In so doing answers to the problem of distinctiveness and diversity might also be found.

\section{A broader debate about strategy development in higher education}

The trends point to a scenario where the formal approaches to strategy development in Irish HEIs in the next decade, at institutional level, will remain in the Classical Masters of the Universe quadrant, an approach that has demonstrable weaknesses in terms of its responsiveness to the environment. Within HEIs, the target-driven nature of the annual strategic dialogue process with the HEA is likely to re-enforce a rational approach to strategy development to ensure that (i) the institution can demonstrate that it takes strategic planning seriously and (ii) that it can provide evidence to demonstrate that its strategic objectives are being achieved. It remains to be seen to what extent decisions taken by the HEA and others will mirror this rational approach, noting the political and other considerations which will come into play. At this point also it is worth pausing to reflect on Brunnson's view of organisational hypocrisy when he contends that organisations talk in a way that satisfies one demand, decide in a way that satisfies another and supply products in a way that satisfies a third (Brunsson 1989). 
If Irish HEIs continue to rely upon rational strategic planning, it is based on the assumption that a strategic plan is vital to future success, that the environment can be mastered and that the future can be predicted with certainty. Even with the enhancements outlined above, the model is inherently ill-suited to cope with the rate of change in the environment. Some aspects of an evolutionary approach to strategy development may therefore be more appropriate in some aspects of an HEI's activities. When Survival of the Fittest becomes the guiding philosophy, responsiveness to the environment becomes paramount and an institution moves forward through innovation, trial and error, continually learning from its mistakes. Leaps of faith are required to switch from established activities to new ideas that may initially be inferior but that promise to be superior in the future. With an evolutionary approach to strategy development, there is no strategic plan, a notion which is likely to sit uncomfortably with funding agencies and with institutional management teams who struggle to direct the activities of academic units into a coherent institutional strategy. If carefully managed and steered, an evolutionary approach does have the potential to harness the greatest resource available to HEIs, its human capital. Likewise aspects of a systemic approach, Playing by Local Rules, which builds on the indigenous and more established quality assurance framework within HEIs and which respects the organisational culture of the academic heartland, may prove a more effective, if less glamorous, approach to strategy development. A wider debate is required, involving all actors including HEIs, funding and quality assurance agencies to consider the fundamental questions posed by the findings of this research is the predominant model for strategic planning in higher education fundamentally mismatched to the social context it is used in and are there better ways to develop strategy in higher education?

\section{Acknowledgements}

The authors wish to acknowledge the support of the Department of Education and Science (Strand 1) research scheme for this project.

\section{References}

Allen, D.K. (2003) 'Organisational climate and strategic change in higher education:

Organisational insecurity', Higher Education 46: 61-92.

Alves, H., Mainardes, E.W. \& Raposo, M. (2010) 'A Relationship Approach to Higher Education Institution Stakeholder Management', Tertiary Education and Management 16(3): 159181.

Aubyn, M. et al. (2009) 'European Economy : Study on the efficiency and effectiveness of public spending on tertiary education', European Commission Directorate-General for Economic and Financial Affairs Publications.

Bain \& Company (2007) 'Management Tools 2007', Company report available at: http://www.bain.com/offices/saopaulo/pt/Images/Management_Tools_2007_BB.pdf. 
Birnbaum, R. (2000) 'The life cycle of academic management fads', Journal of Higher Education 71(1): 1-16.

Brunsson, N. (1989) The organisation of hypocrisy: Talk, decisions and actions in organisations, John Wiley.

Bruton, M.J. (1987) 'University planning and management in conditions of complexity and uncertainty', Higher Education Quarterly 41(4).

ENQA (2005) 'European Standards and Guidelines for Quality Assurance', European Association for Quality Assurance in Higher Education.

EUA (2012) 'European University Association Institutional Evaluation Programme'. Guidelines available at: http://www.eua.be.

Freeman, R.E. (2010) Strategic management: A stakeholder approach, Cambridge University Press.

Government of Ireland (1994). 'Dublin Institute of Technology (Amendment) Act, 1994', Available at: http://www.irishstatutebook.ie.

Government of Ireland (1997) 'Universities Act 1997', Available at: http://www.irishstatutebook.ie.

Government of Ireland (1999) 'Qualifications Act, 1999', Available at: http://www.irishstatutebook.ie.

Government of Ireland (2006) 'Institutes of Technology Act 2006', Available at: http://www.irishstatutebook.ie.

Government of Ireland (2011) 'Report of the Research Prioritisation Steering Group', Department of Jobs, Enterprise and Innovation.

HEA (2011a) 'National Strategy for Higher Education to 2030', Higher Education Authority, Available at: http://www.hea.ie.

HEA (2011b) 'HEA Student Statistics 2010/11', Higher Education Authority, Available at: http://www.hea.ie [Accessed January 29, 2012].

HEA (2012) 'Towards a Future Higher Education Landscape', Higher Education Authority, Available at: http://www.hea.ie/files/TowardsaFutureHigherEducationLandscape.pdf.

IOTI (2011) 'ESTIP - Empowering Staff through Institutional Planning', Strategic Innovation Fund - Institutes of Technology Ireland. Available at: http://ww2.dkit.ie/staff_and_admin/strategy/activities/estip_framework/estip_frame work_reference_manual.

IUQB (2008) 'National Guidelines of Good Practice in Strategic Planning for Academic Units in Irish Universities', Irish Universities Quality Board. Available at: http://www.iuqb.ie/info/good_practice_guides.aspx?article=8f812a10-f642-4e5e-95bc51f00be0db9b.

James, H. \& Huisman, J. (2009) 'Missions statements in Wales: the impact of markets and policy on congruence between institutions', Journal of Higher Education Policy \& Management, 31(1):23-35.

Lillis, D. (2007) 'Steering by engagement - towards an integrated planning and evaluation framework for higher education', EUA Case Studies 2007 - Embedding quality culture in higher education. 
Lillis, D. (2006) 'The systematic evaluation of a strategic management program in an Irish institute of technology', Tertiary Education and Management, 12(3) : 241-256.

McGuinness, S. et al. (2012) 'A Study of Future Demand for Higher Education in Ireland', The Economic and Social Research Institute, Dublin.

NQAI (2001) 'National Qualifications Framework of Ireland : A Framework for the development, recognition and award qualifications in Ireland', National Qualifications Authority of Ireland.

OECD (2010) 'Education at a Glance 2010', Organisation for Economic Co-Operation. Available at: http://www.oecd.org/dataoecd/45/39/45926093.pdf.

Porter, M. (1985) Competitive advantage : Creating and sustaining superior performance, New York: The Free Press.

Tabatoni, P., Davies, J. \& Barblan, A. (2004) Strategic management and Universities' institutional development, European University Association.

Thys-Clement, F. \& Wilkin, L. (1998) 'Strategic management and universities: Outcomes of a European survey', Higher Education Management, 10(1) : 13-28.

van Vught, F. et al. (2010) 'U-Map'. The European Classification of Higher Education Institutes. Available at: http://www.u-map.org.

Whittington, R. (2001) 'What is Strategy - and does it matter?' South-Western CENGAGE Learning. United Kingdom: 
Figure 1 Approaches to strategy development - Adapted from Whittington (2001)

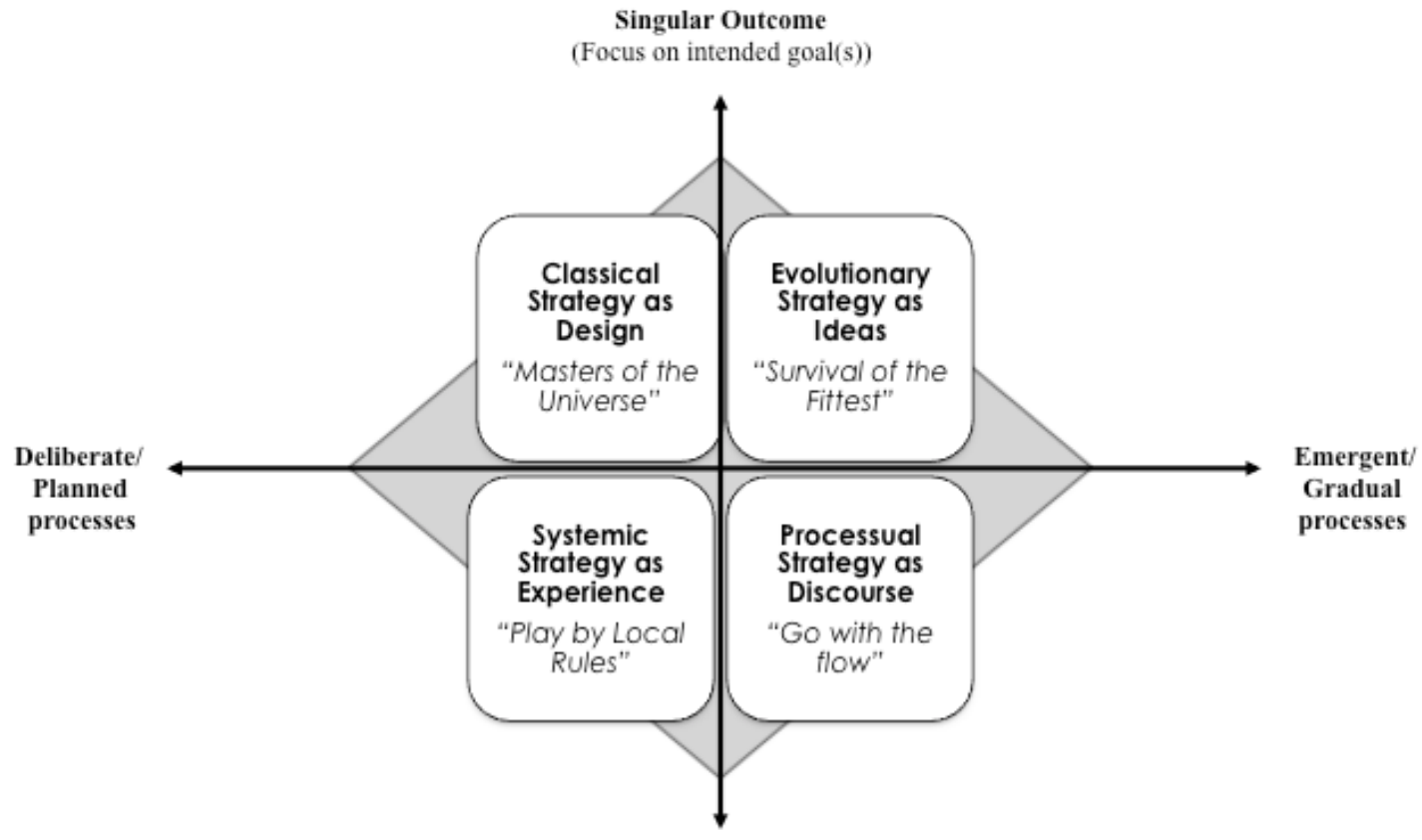

Pluralistic Outcomes

(Alows for many possible outcomes, both intended and unintended)

Adapted by the authors for use in a higher education context from (Whittington, 2001) and (Johnson and Scholes, 2002) 
Figure 2 The relationship between strategic planning and institutional review
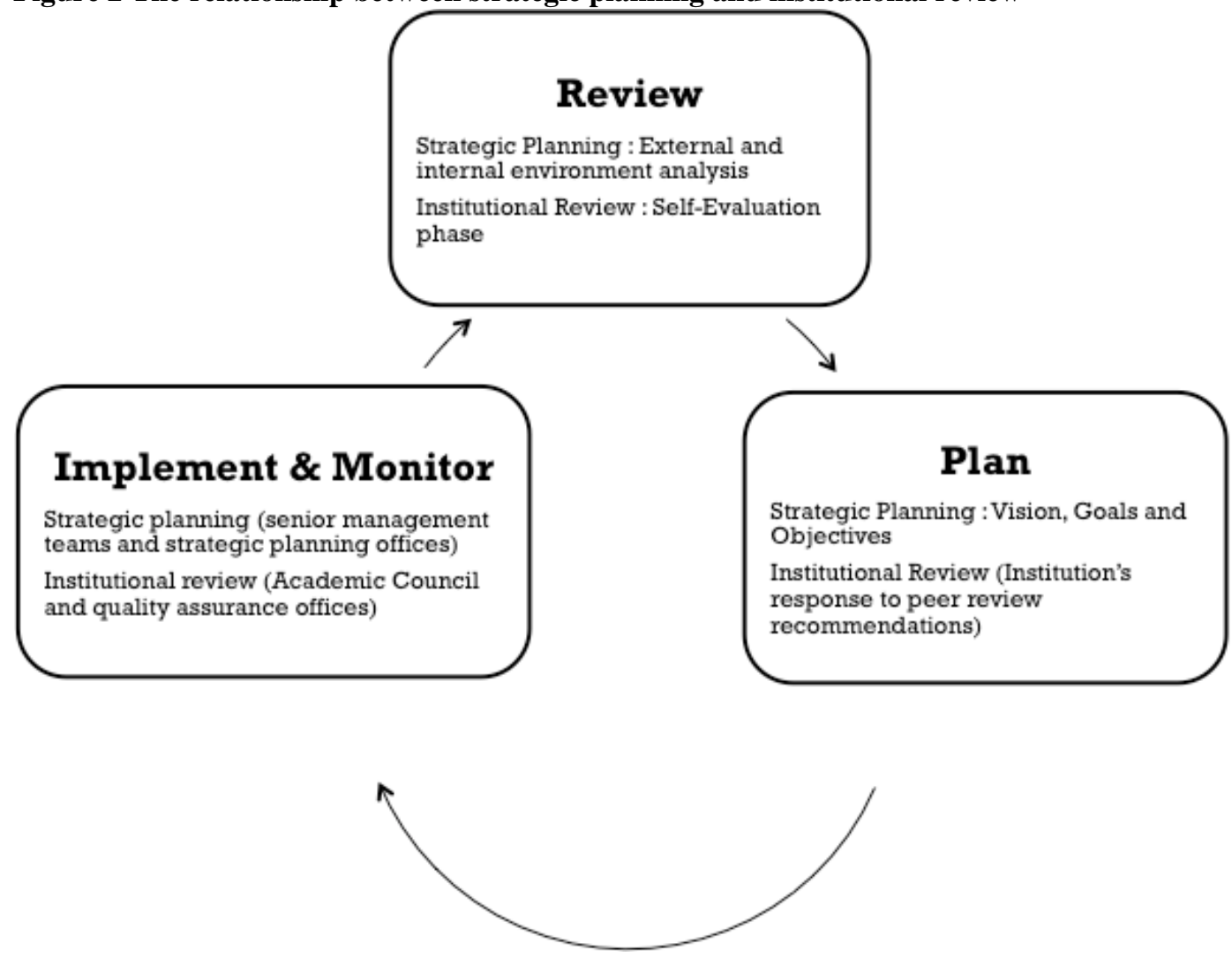


\begin{tabular}{|c|c|c|c|c|}
\hline & $\begin{array}{l}\text { Classical } \\
\text { "Masters of our } \\
\text { Universe" }\end{array}$ & $\begin{array}{l}\text { Processual } \\
\text { "Go with the flow" }\end{array}$ & $\begin{array}{l}\text { Evolutionary } \\
\text { "Survival of the } \\
\text { Fittest" }\end{array}$ & $\begin{array}{l}\text { Systemic } \\
\text { "Play by local } \\
\text { rules" }\end{array}$ \\
\hline Strategy & Formal & Crafted & Efficient & Embedded \\
\hline Rationale & Profit Maximisation & Vague & Survival & Local \\
\hline Focus & Internal (plans) & Internal (politics) & External (markets) & External (society) \\
\hline Processes & Analytical & Bargaining/Learning & Darwinian & Social \\
\hline Key influences & Economics/military & Psychology & Economics/Biology & Sociology \\
\hline Key authors & $\begin{array}{l}\text { Mintzberg (Design } \\
\text { School) } \\
\text { Johnson \& Scholes } \\
\text { (Strategy as Design) } \\
\text { Chandler } \\
\text { Ansoff } \\
\text { Porter }\end{array}$ & $\begin{array}{l}\text { Cyert \& March } \\
\text { Mintzberg (Learning } \\
\text { School, Power } \\
\text { School) } \\
\text { Johnson \& Scholes } \\
\text { (Strategy as } \\
\text { Discourse) } \\
\text { Pettigrew }\end{array}$ & $\begin{array}{l}\text { Mintzberg } \\
\text { (Entrepreneurial } \\
\text { School, } \\
\text { Environment } \\
\text { School) } \\
\text { Johnson \& Scholes } \\
\text { (Strategy as Ideas) } \\
\text { Hannan \& Freeman } \\
\text { Williamson }\end{array}$ & $\begin{array}{l}\text { Mintzberg } \\
\text { (Cultural School) } \\
\text { Granovetter } \\
\text { Marris } \\
\text { Johnson \& } \\
\text { Scholes } \\
\text { (Strategy as } \\
\text { Experience) }\end{array}$ \\
\hline Key Period & 1960's & 1970's & 1980's & 1990's \\
\hline
\end{tabular}


Table 2 Nature of staff, student and stakeholder involvement

\begin{tabular}{|l|c|c|c|c|}
\hline \multicolumn{1}{|c|}{ Type of involvement } & $\begin{array}{c}\text { Staff } \\
\text { Involvement } \\
\text { (No. of } \\
\text { Institutions) }\end{array}$ & $\begin{array}{c}\text { Student } \\
\text { Involvement } \\
\text { (No. of } \\
\text { Institutions) }\end{array}$ & $\begin{array}{c}\text { Industry } \\
\text { Involvement } \\
\text { (No. of } \\
\text { Institutions) }\end{array}$ & $\begin{array}{c}\text { Community } \\
\text { Stakeholder } \\
\text { Involvement } \\
\text { (No. of } \\
\text { Institutions) }\end{array}$ \\
\hline $\begin{array}{l}\text { Special Strategic Planning } \\
\text { meetings }\end{array}$ & 11 & 1 & 1 & 1 \\
\hline Strategic Planning Steering Group & 8 & - & - & - \\
\hline $\begin{array}{l}\text { Focus groups and workshops on } \\
\text { specific themes/goals }\end{array}$ & 8 & 3 & 2 & 2 \\
\hline $\begin{array}{l}\text { Drafts documents circulated for } \\
\text { feedback }\end{array}$ & 8 & 1 & 2 & - \\
\hline Questionnaires & 5 & 1 & - & - \\
\hline $\begin{array}{l}\text { Presentations / Information } \\
\text { sessions }\end{array}$ & 5 & 2 & 2 & - \\
\hline Interviews & 2 & - & - & 1 \\
\hline
\end{tabular}

